\title{
The Microstructure Evolution and Its Effect on Corrosion Properties of 18Cr-12Ni-2,5Mo Steel Annealed at $500-900^{\circ} \mathrm{C}$
}

\section{Mária Dománková, Edina Kocsisová, Ivan Slatkovský, Peter Pinke}

Institute of Materials Science, Faculty of Material Science and Technology in Trnava, Slovak University of Technology in Bratislava, Bottova 25, 91724 Trnava, Slovakia, e-mail: maria.domankova@stuba.sk, edina.kocsisova@stuba.sk, ivan.slatkovsky@stuba.sk,peter.pinke@stuba.sk

\begin{abstract}
The process of the secondary phases precipitation controls the mechanical and physical properties of the stainless steels. The process of precipitation and its influence on corrosion resistance was analysed in the experimental steel AISI 316. The corrosion test ASTM A 262 practice A was used for evaluation of the experimental steel to intergranular corrosion. Results showed that the solution-annealed samples $\left(1100^{\circ} \mathrm{C} / 1 \mathrm{~h}-\right.$ followed by water quenching) did not present susceptibility to intergranular corrosion. The heat treatment in the range from 500 to $900^{\circ} \mathrm{C}$ resulted in susceptibility to intergranular attack. Precipitation of carbide $M_{23} C_{6}$ accelerates sensitisation of the experimental steel. Increasing of holding time cased precipitation $\sigma$-phase and carbide $M_{6} C$, which were detected at grain boundaries. Transmission electron microscopy was used for identification of particles at the grain boundaries, measurement of their size and studied of their morphology.
\end{abstract}

Keywords: austenitic stainless steel; precipitation; sensitisation; intergranular corrosion

\section{Introduction}

Intergranular corrosion (IGC) and stress corrosion cracking (SCC) of austenitic stainless steels (ASSs) are the most important corrosion process that affects the service behaviour of these materials. Austenitic stainless steels are the most favoured construction materials of various components required in chemical, petrochemical and nuclear industries. The selection of these is made basically due to a good combination of mechanical, fabrication and corrosion resistance properties. But austenitic stainless steels which have undergone treatment in the temperature range between $500-900^{\circ} \mathrm{C}$ or have been cooled slowly from annealing temperatures $\left(1000-1200^{\circ} \mathrm{C}\right)$ become sensitised. The phenomenon of sensitisation 
in stainless steels refers to their susceptibility to intergranular corrosion resulting from microstructural changes. Grain boundary chemistry is known to be a critical factors impacting structural reliability of ASSs [1-3, 11-14]. If the chromium content near the grain boundaries drops under the passivity limit $12 \mathrm{wt} . \%$, the steel becomes to be sensitised. In the sensitised condition, the steels are quite susceptible to the intergranular corrosion (IGC) and intergranular stress corrosion cracking (IGSCC) that can result in premature failures of the fabricated components. The sensitisation temperature range is often encountered during isothermal heat treatment, slow cooling from the solution annealing temperature, the improper heat treatment in the heat affected zone of the welds or welding joints or hot working of the material [4-6].

Degree of the sensitisation (DOS) is influenced by factors such as the steel chemical composition, grain size, degree of strain or temperature and time of isothermal annealing [5-7]. The sensitisation involves both nucleation and growth of intermetallic phases at the grain boundaries. Sensitisation resulting from isothermal exposure is normally represented by time-temperature-sensitisation (TTS) diagrams, which are plots of aging time versus temperature necessary for sensitisation. These are $\mathrm{C}$ - shaped curves, which separate sensitised and nonsensitised regions. The TTS diagrams show the time required for isothermal sensitisation at various temperatures and can be used to solve problems such as the selection of conditions of annealing which will not result in sensitisation. The nose of this curve specifies the critical temperature at which the minimum time $\left(\mathrm{t}_{\min }\right)$ is required for sensitisation $[13,14]$. The ageing reactions, nature of precipitates, and precipitation kinetics during high-temperature exposure were studied in the past. The weight fraction of carbides was often assess by dint of the usual electrochemical dissolution methods, applied to austenitic stainless steels with high carbon contents. The use of analytical electron microscopy has allowed the chromium distribution at grain boundaries to be measured and it was possible to compare these results with value predicted by different models [8].

However, in austenitic stainless steels except chromium also other alloying elements may effect and change the precipitate consequention or kind of precipitates. For instance Hull [9] investigated a great number of standard carbon and nitrogen free iron-chromium-nickel alloys with regard to the alloying addition influence on the precipitation of $\sigma$-phase and $\chi$-phase at the temperature $816^{\circ} \mathrm{C}$ and precipitation times up to 1000 hours. From the data obtained, he calculate the chromium equivalent for the material embrittlement connected to $\sigma$-phase formation:

$$
\begin{aligned}
& \mathrm{Cr}_{\text {eqv }}=\% \mathrm{Cr}+0,31 \% \mathrm{Mn}+1,7 \% \mathrm{Mo}+1,58 \% \mathrm{Si}+ \\
& +2,44 \% \mathrm{Ti}+1,22 \% \mathrm{Ta}+0,97 \% \mathrm{~W}-0,266 \% \mathrm{Ni}-0,177 \% \mathrm{Co}
\end{aligned}
$$

In this research article, we report of the effects temperature and aging time on sensitisation and precipitation of the secondary phases in AISI 316 stainless steel. 


\section{Material and Experimental Procedures}

Wrought austenitic stainless steel AISI 316 containing $1 \%$ of $\delta$-ferrite was used during the course of this investigation and its chemical composition is given in Table 1. All samples were solution heat-treated at $1100^{\circ} \mathrm{C} / 1 \mathrm{~h}$. followed by water quenching. The samples were heat treated at various temperatures from 500 to $900^{\circ} \mathrm{C}$ for duration range from $10 \mathrm{~min}$. to $1000 \mathrm{~h}$ in evacuated tubes. The samples were water quenched after the heat treatments.

Table 1

Chemical composition (in wt.\%) of austenitic stainless steel

\begin{tabular}{|c|c|c|c|c|c|c|c|c|c|c|}
\hline Steel & $\mathrm{C}$ & $\mathrm{N}$ & $\mathrm{Si}$ & $\mathrm{Mn}$ & $\mathrm{P}$ & $\mathrm{S}$ & $\mathrm{Cr}$ & $\mathrm{Ni}$ & $\mathrm{Mo}$ & $\mathrm{Fe}$ \\
\hline AISI 316 & 0,05 & 0,032 & 0,47 & 0,86 & 0,003 & 0,001 & 17,55 & 11,56 & 2,10 & Bal. \\
\hline
\end{tabular}

The specimens for light optical microscopy (LOM) examination were polished up to fine diamond $(\sim 1 \mu \mathrm{m})$ finish. The specimens were etched chemically for $60 \mathrm{sec}$. using solution: $10 \mathrm{ml} \mathrm{H}_{2} \mathrm{SO}_{4}+10 \mathrm{ml} \mathrm{HNO}_{3}+20 \mathrm{ml} \mathrm{HF}+50 \mathrm{ml}$ distilled $\mathrm{H}_{2} \mathrm{O}$. Then the screening of microstructures was done using a light microscope NEOPHOT 32 equipped with the CCD camera.

The oxalic acid etch test was used for the determination of steel sensitivity to intergranular corrosion. The specimens were electrolytically etched in $10 \%$ oxalic acid for $90 \mathrm{sec}$. at a current density of $1 \mathrm{~A} / \mathrm{cm}^{2}$. The etched microstructures were then examined at 250x and were classified into the following types [10, 12, 1416]:

- step structure: steps only between grains, no ditches at grain boundaries,

- dual structure: some ditches at grain boundaries, but no single grain completely surrounded by ditches,

- ditch structure: one or more grains completely surrounded by ditches and the steel is classified as sensitised in this case. The steel is susceptible to the intergranular corrosion.

For the individual secondary phase identification transmission electron microscopy (TEM) of the extraction carbon replicas was utilised. The carbon extraction replicas were obtained from mechanically polished and etched surfaces. The replicas were stripped from the specimens in the solution of $\mathrm{CH}_{3} \mathrm{COOH}$ : $\mathrm{HClO}_{4}=4: 1$ at $20^{\circ} \mathrm{C}, 20 \mathrm{~V}$ [15].

Thin foils suitable for transmission electron microscopy (TEM) observation were prepared from each of the samples. Small discs of $3 \mathrm{~mm}$ in diameter and thick about $0.1 \mathrm{~mm}$ were jet-electropolished in electrolyte $\mathrm{HNO}_{3}: \mathrm{CH}_{3} \mathrm{OH}=3: 7$, at $0^{\circ} \mathrm{C}$ and $15 \mathrm{~V}$ to obtain transparent areas near the central hole. The jetelectropolishing was done by TENUPOL 5 . 
TEM observations were performed using JEOL $200 \mathrm{CX}$ operated at $200 \mathrm{kV}$ and Philips CM 300 operating at $300 \mathrm{kV}$ equipped with energy-dispersive X-ray spectrometer (EDX), which was used for the microchemical analyses. The analysis was supplemented by selected area electron diffraction for the phases identification.

\section{Results}

\subsection{LOM Observations}

The results of the light microscopy (LOM) examination are summarised in Fig. 1. The microstructure of AISI 316 after solution annealing consists of polyhedral austenitic grains with twinning typical for fcc microstructure. The average austenitic grain size in this state is about $35 \pm 5 \mu \mathrm{m}$ (Fig. 1a). A small amount of $\delta$ ferrite was also recorded. No precipitates were observed at the grain boundaries (GB) of solution annealed steels. The microstructures of aged states are shown in Fig. 1b-1d.
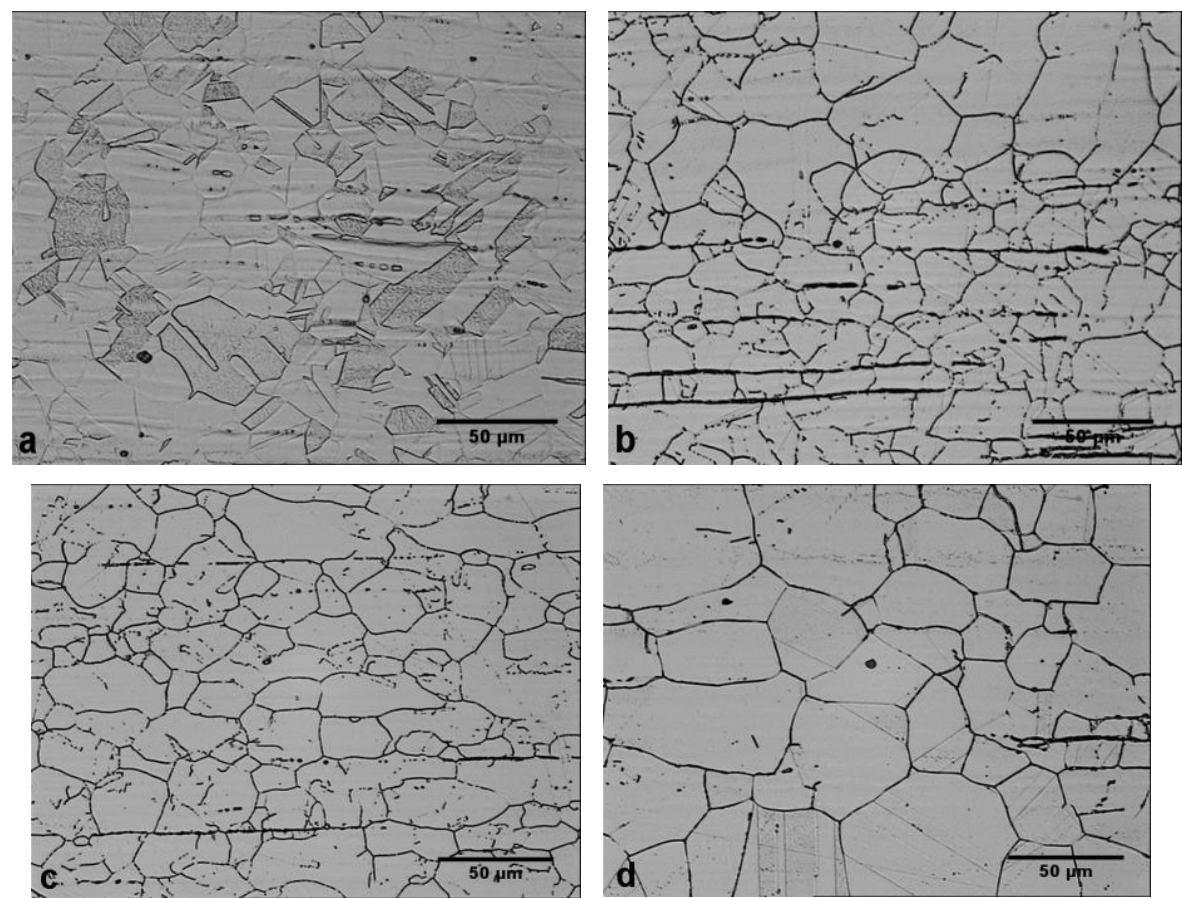

Figure 1

Microstructure of AISI 316 a) after solution annealing, b) after aging $750^{\circ} \mathrm{C} / 1 \mathrm{~h}, \mathrm{c}$ ) after aging $\left.750^{\circ} \mathrm{C} / 300 \mathrm{~h}, \mathrm{~d}\right)$ after aging $750^{\circ} \mathrm{C} / 1000 \mathrm{~h}$ 
Significant etching of grain boundaries was observed by LOM with increasing of holding time at the temperature. This effect is caused by precipitation of secondary phases at the grain boundaries. Fig. 1b shows the evolution of the precipitation at the GB in the isothermally aged sample $\left(750^{\circ} \mathrm{C} / 1 \mathrm{~h}\right)$. Fig. $1 \mathrm{c}$ shows microstructure in the isothermally aged sample $\left(750^{\circ} \mathrm{C} / 300 \mathrm{~h}\right)$ and Fig. $1 \mathrm{~d}$ shows microstructure of the sample after the heat treatment $750^{\circ} \mathrm{C} / 1000 \mathrm{~h}$. The growth of grains was observed in the case of this sample. The average austenitic grain size is about $60 \pm 8 \mu \mathrm{m}$ (Fig. 1d).

The rapid oxalic acid etch test was used for analysis of the grain boundary sensitisation development. Examples of microstructure obtained by etch test for AISI 316 are given in Fig. 2. TTS diagram was obtained by plotting sensitisation test results on a temperature versus log soaking time axes and drawing a line which demarcates the sensitised and non-sensitised regions (Fig. 3). The nose of this curve for the experimental steel AISI 316 was at the temperature $800^{\circ} \mathrm{C}$ and $\mathrm{t}_{\min }=20 \mathrm{~min}$.
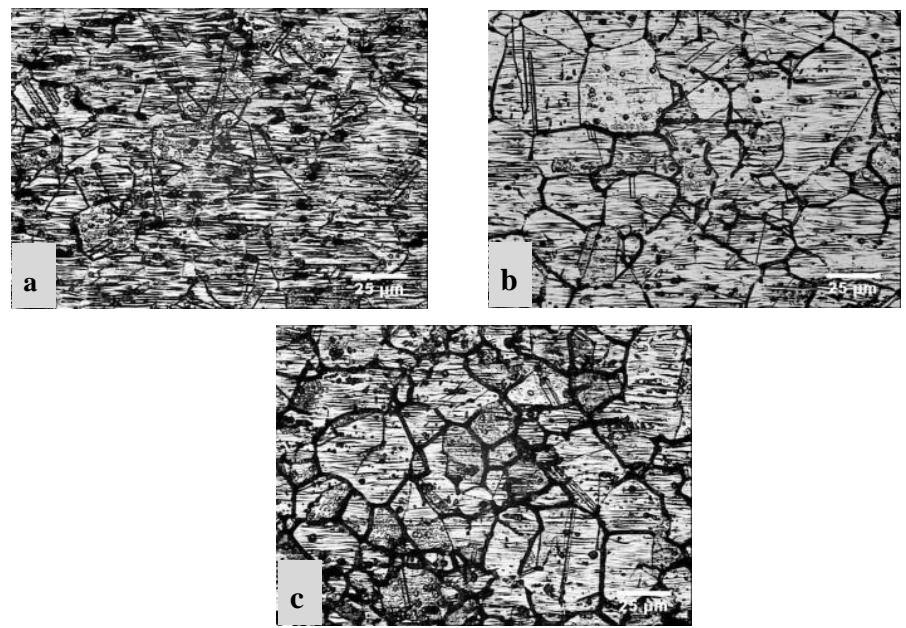

Figure 2

Examples of AISI 316 microstructure obtained after oxalic acid etch test a) after solution annealing (step), b) after aging $800^{\circ} \mathrm{C} / 10 \mathrm{~min}$. (dual), c) after aging $800^{\circ} \mathrm{C} / 10 \mathrm{~h}$ (ditch)

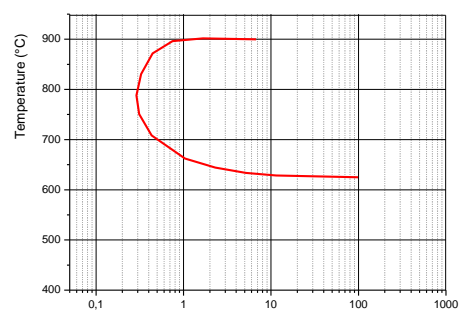

Figure 3

TTS diagram for AISI type 316 austenitic stainless steel established according to the test ASTM A262 practice A 


\subsection{TEM Observations}

The TEM microstructure analysis was focused especially on the identification of secondary phases, which precipitated at the grain boundaries during the annealing. The changes of chemical composition and the relative size of particles were evaluated. Fig. 4 shows the microstructure of AISI 316 in the solution annealing state observed by TEM using carbon replica. The pure grain boundaries are documented by the figures. Fig. 5 shows the typical GBs formed in an early stage of the aging treatment $\left(750^{\circ} \mathrm{C} / 10 \mathrm{~min}\right.$.), only a few particles of secondary phase were observed at the grain boundaries using TEM. As first $\mathrm{M}_{23} \mathrm{C}_{6}$ carbide at the austenitic grain boundaries was detected (Fig. 6). Besides $\mathrm{M}_{23} \mathrm{C}_{6}$ carbide, $\sigma$-phase and $\mathrm{M}_{6} \mathrm{C}$ carbide were detected at the grain boundaries. The density and size of precipitates at the grain boundaries growth with increasing of the aging time (Fig. 7 and Fig. 8).

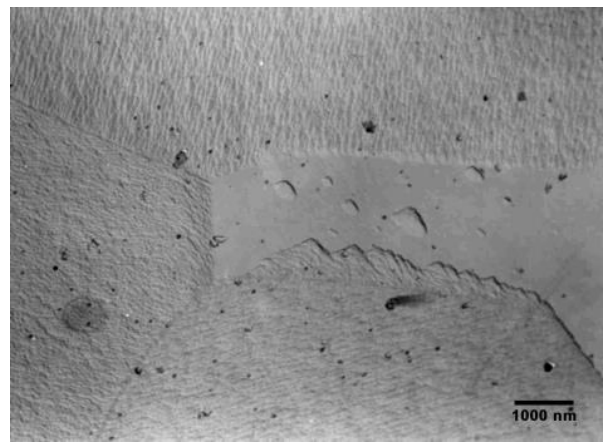

Figure 4

Microstructure of AISI 316 in the solution annealing state

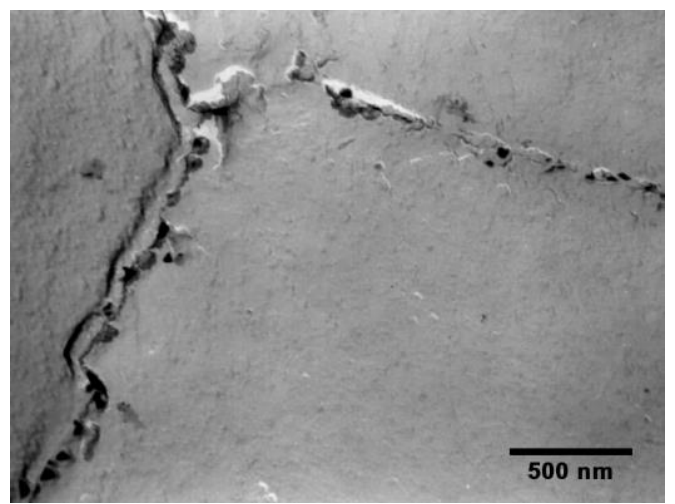

Figure 5

Precipitation of $\mathrm{M}_{23} \mathrm{C}_{6}$ carbide at the $\mathrm{GB}$ - after aging $750^{\circ} \mathrm{C} / 10 \mathrm{~min}$. 

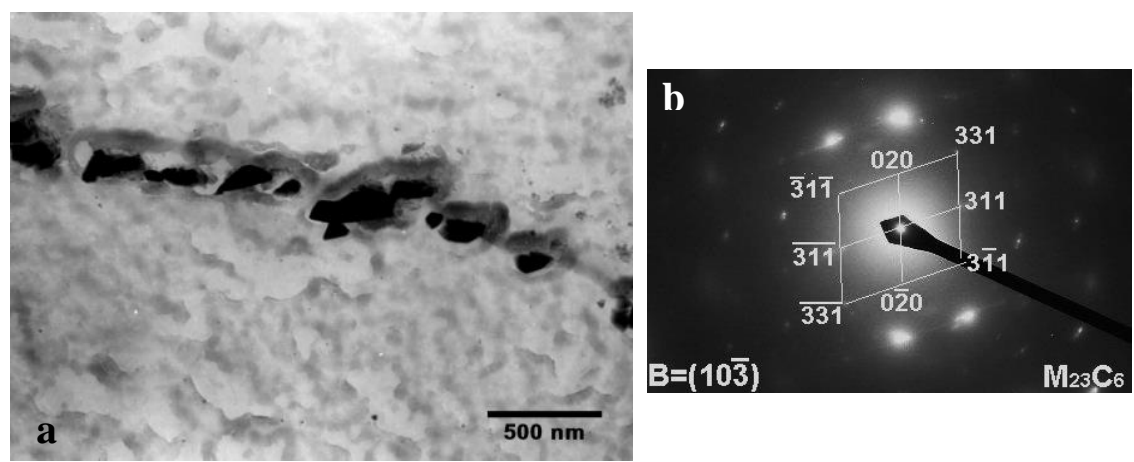

Figure 6

a) Detail of the grain boundary with particles of irregular shape after aging $750^{\circ} \mathrm{C} / 5 \mathrm{~h}, \mathrm{~b}$ ) particles were identified by SAED as carbide $\mathrm{M}_{23} \mathrm{C}_{6}$

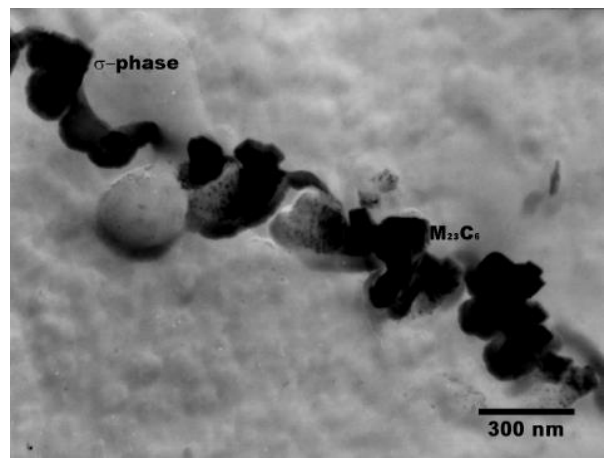

Figure 7

Precipitation of secondary phases at the grain boundary after aging $750^{\circ} \mathrm{C} / 300 \mathrm{~h}$

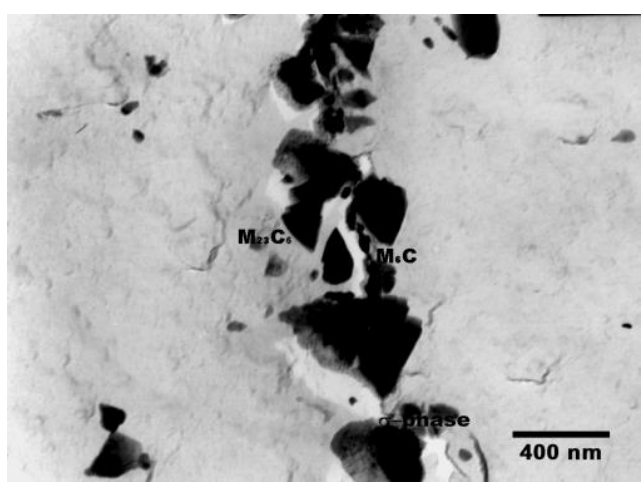

Figure 8

Precipitation of secondary phases at the grain boundary after aging $750^{\circ} \mathrm{C} / 1000 \mathrm{~h}$ 
The change of the particles size during aging at the temperature $750{ }^{\circ} \mathrm{C}$ is shown in Fig. 9. The medium size of particles increased from $40 \mathrm{~nm}$ to $120 \mathrm{~nm}$. The maximum of the particles size was found at the temperature at $750^{\circ} \mathrm{C}$ with holding time 30h. Subsequently the medium particles size decreased with increasing of holding time. In our opinion decreasing of particles size was caused by the change of phase composition in the experimental steel. Carbide $\mathrm{M}_{23} \mathrm{C}_{6}$ content decreased and content of carbide $\mathrm{M}_{6} \mathrm{C}$ increased.

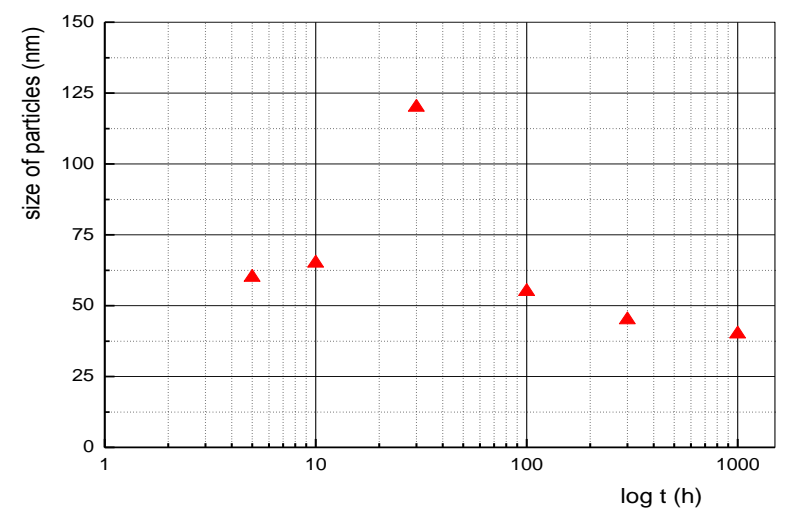

Figure 9

Growth of the particles in the experimental steel AISI 316 after aging at the temperature $750^{\circ} \mathrm{C}$

Fig. 10 summarises the average metal composition of carbide $\mathrm{M}_{23} \mathrm{C}_{6}$ after the aging treatment at the temperature $750^{\circ} \mathrm{C}$ measured by EDX analysis. The measurement of chemical composition shows the slight growth of the chromium contain with increasing of the aging time.

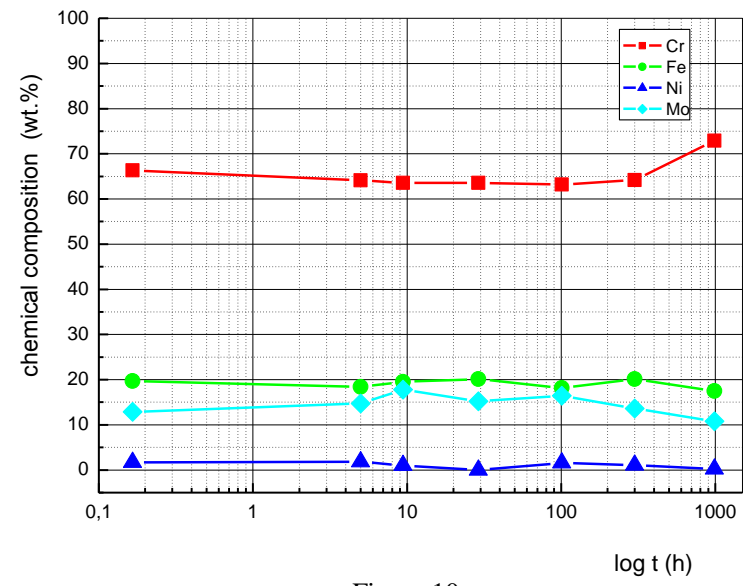

Figure 10

Changes of the chemical composition of carbide $\mathrm{M}_{23} \mathrm{C}_{6}$ during annealing at the temperature $750^{\circ} \mathrm{C}$ 
Fig. 11 shows the changes of chemical composition of $\sigma$-phase during the annealing at the temperature $750^{\circ} \mathrm{C}$. The main element of this phase is iron, and a slight increase in Fe content can be observed as a function of increasing aging time. The changes of other elements were not significant. The changes of chemical composition of the carbide $\mathrm{M}_{6} \mathrm{C}$ is shown by Fig. 12. The main element of this phase is molybdenum. The significant changes of the chemical composition of the carbide $\mathrm{M}_{6} \mathrm{C}$ during the annealing were not observed by EDX analysis.

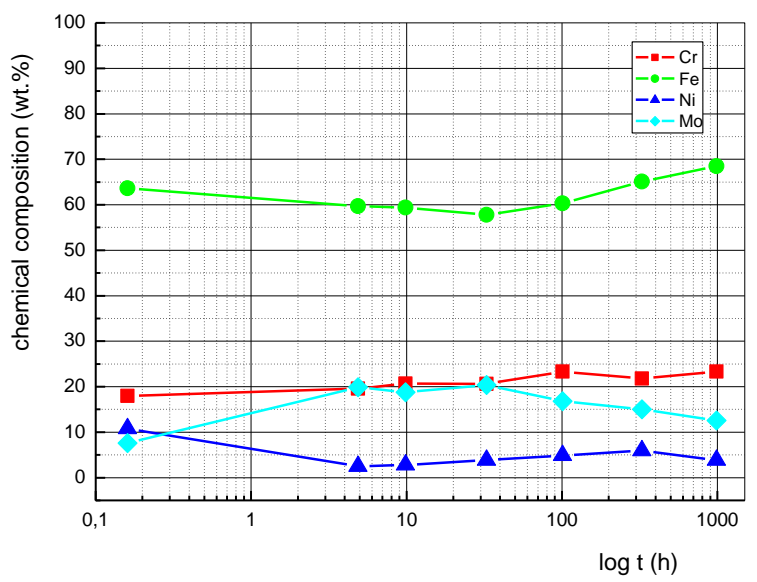

Figure 11

Changes of the chemical composition of $\sigma$-phase during annealing at the temperature $750^{\circ} \mathrm{C}$

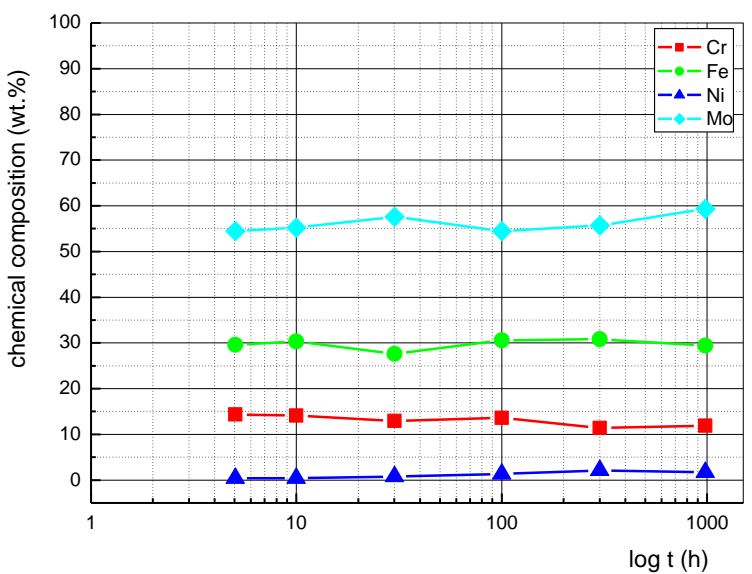

Figure 12

Changes of the chemical composition of carbide $\mathrm{M}_{6} \mathrm{C}$ during annealing at the temperature $750^{\circ} \mathrm{C}$ 
The changing fractions of identified secondary phases in steel AISI 316 during aging at temperature $750^{\circ} \mathrm{C}$ are demonstrated in Fig. 13 .

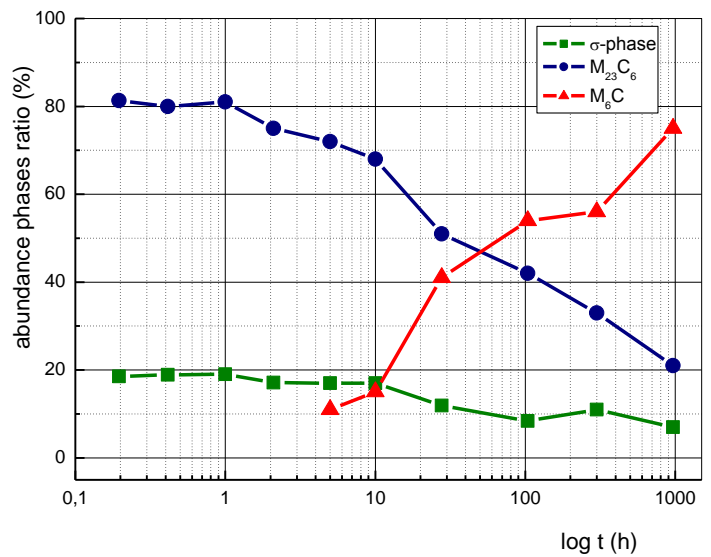

Figure 13

Fractions of the secondary phases in AISI 316 after aging at the temperature $750^{\circ} \mathrm{C}$

Fig. 14 shows substructure of the experimental steel after solution annealing observed using thin foils. The grain boundaries were pure without precipitates. Fig. 15 shows details of the substructure after annealing $800^{\circ} \mathrm{C} / 10 \mathrm{~min}$ - early stage of the precipitation process. The small precipitates of irregular shape were observed at some grain boundaries. EDX line analysis across the boundary (Fig. 16) did not show the change of the chemical composition between the matrix and the grain boundary in the case of solution annealed state. Small decreasing of chromium contain across the boundary was found by EDX line analysis across the boundary (Fig. 16), but chromium content was sufficient to maintain of corrosion resistance of experimental steel. Precipitation during heat treatment $800^{\circ} \mathrm{C} / 10 \mathrm{~min}$ did not cause sensitisation of the steel AISI 316. This results is in good agreement with results of the rapid oxalic acid etch test and construction of TTS diagram (Fig. 3), respectively.

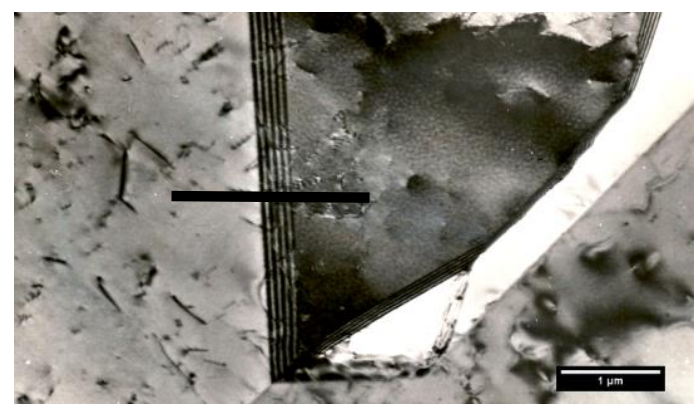

Figure 14

Details of the grain boundaries in the experimental steel after solution annealing (line marked area of EDX analysis) 


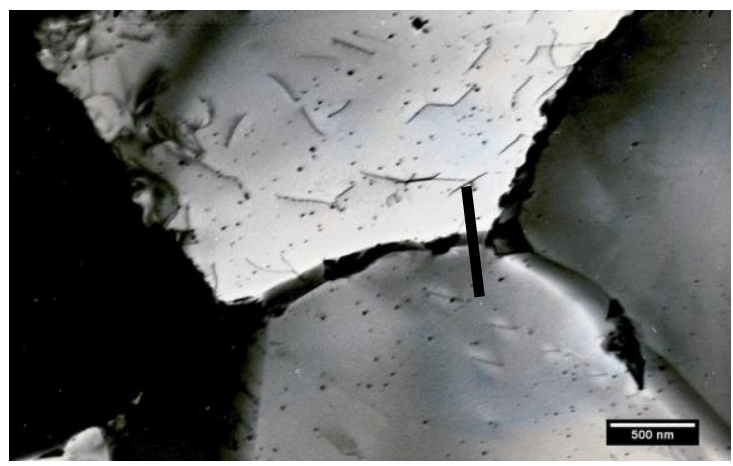

Figure 15

Details of the grain boundaries in the experimental steel after annealing $800^{\circ} \mathrm{C} / 10 \mathrm{~min}$ (line marked area of EDX analysis)

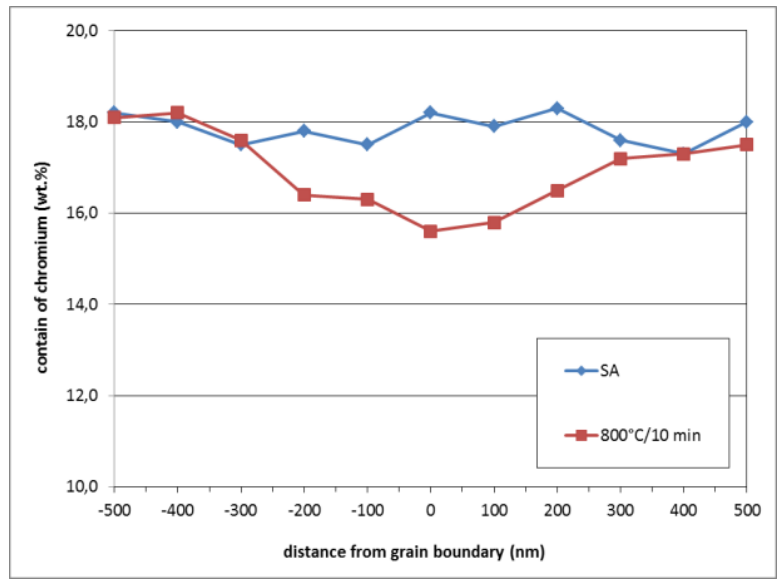

Figure 16

Changes of chromium contain in the area of grain boundary in the experimental steel after solution annealing (SA) and heat treatment $800^{\circ} \mathrm{C} / 10$ min measured by EDX analysis

\section{Conclusions}

The precipitation behaviour of AISI 316 austenitic stainless steel has been investigated in the temperatures range from 500 to $900^{\circ} \mathrm{C}$ for duration range from $10 \mathrm{~min}$ to $1000 \mathrm{~h}$. The following conclusions were drawn:

1. TTS diagrams of experimental steel after oxalic acid etch test ASTM A262 practice A were constructed. The nose of this curve was at the temperature $800^{\circ} \mathrm{C}$ and $t_{\min }=20 \mathrm{~min}$.

2. Sensitisation of the experimental steel accelerated the precipitation of the carbide $\mathrm{M}_{23} \mathrm{C}_{6}$, besides carbide $\mathrm{M}_{23} \mathrm{C}_{6}, \sigma$-phase and carbide $\mathrm{M}_{6} \mathrm{C}$ were detected at the austenitic grain boundaries (Fig. 12). 
3. The medium size of particles increased from $40 \mathrm{~nm}$ to $110 \mathrm{~nm}$ with increasing of holding time during the heat treatment.

4. The measurements of the chemical composition of the secondary phases showed slight increasing the main elements (chromium and iron) in the case of the carbide $\mathrm{M}_{23} \mathrm{C}_{6}$ and $\sigma$-phase with increasing of the time annealing.

5. The small decreasing of chromium contain near of the grain boundary after heat treatment $800^{\circ} \mathrm{C} / 10$ min was found by $\mathrm{EDX}$ line measurement, but the chromium content was sufficient to maintain of corrosion resistance of experimental steel.

\section{Acknowledgement}

The authors wish to thank the financial support of Scientific Grant Agency of Slovak Republic (VEGA) under grant No. 1/0402/13

\section{References}

[1] Lo, K. K.; Shek, C. H.; Lai, J. K. L.: Recent Developments in Stainless Steels. In: Materials Science and Engineering:R:Reports, 65(2009), pp. 39104

[2] Tavares, S. S. M.; Moura, V.; da Costa, V. C.; Fereira, M. L. R.; Pardal, J. M.: Microstructural Changes and Corrosion Resistance of 310S Steel Exposed to $600-800^{\circ} \mathrm{C}$. In: Material Characterization, 60 (2009), pp. 573 578

[3] Nikulin, I.; Kipelova, A.; Kaibyshev, R.: Effect of High-Temperature Exposure on the Mechanical Properties of $18 \mathrm{Cr}-8 \mathrm{Ni}-\mathrm{W}-\mathrm{Nb}-\mathrm{V}-\mathrm{N}$ Stainless Steel. In: Materials Science and Engineering A 554 (2012), pp. 61-66

[4] Kanek, K.; Fukunaga, T.; Yamada, K.; Nakada, N.; Kikuchi, M.; Saghi, Z.; Barnard, J. S.; Midgley, P. A.: Formation of $\mathrm{M}_{23} \mathrm{C}_{6}-$ Type Precipitates and Chromium-depleted Zones in Austenitic Stainless Steel. In: Scripta Materialia 65 (2012), pp. 509-512

[5] Ahmadabadi, P. M.; Kain, V.; Dang, B. K., Samajdar, I.: Role of Grain Boundary Nature and Residual Strain in Controlling Sensitisation of Type 304 Stainless Steel. In: Corrosion Science 66(2013), pp. 242-255

[6] Bitay, E.; Kovacs, T.: The Effect of Laser Surface Treatment on the Wear Resistance. In: Materials Science Forum 649 (2010), pp. 107-112

[7] Tsay, L. W.; Lin, Y. J.; Chen, C.: The Effects of Rolling Temperature and Sensitisation Treatment on the Sulphide Stress Corrosion Cracking of 304 L Stainless Steel. In: Corrosion Science 63 (2012), pp. 267-274

[8] Sanzay, M.; Barard, K.; Karlen, W.: TEM Observation and Finite Element Modelling of Channel Deformation in Pre-irradiated Austenitic Stainless Steels - Interactions with the Surfaces and Grain Boundaries. In: Journal of Nuclear Materials 406 (2010), pp. 152-165 
[9] Hull, F. C.: Effects of Composition on Embrittlement of Austenitic Stainless Steels. In: Welding Journal 52 (1973), pp. 104-113

[10] ASTM Standard Practice in A 262 for Detecting Susceptibility to Intergranular Corrosion in Austenitic Stainless Steels

[11] Leiva-García, R.; Munoz-Portero, M. J.; García-Antón, J.: Evaluation of Alloy 146, 279, 900 and 926 Sensitization to Intergranular Corrosion by Means of Electrochemical Methods and Image Analysis. In: Corrosion Science 51 (2009), pp. 2080-2091

[12] Záhumenský, P.; Tuleja, S.; Országová, J.; Janovec, J., Siládiová, V.: Corrosion Resistance of $18 \mathrm{Cr}-12 \mathrm{Ni}-2,5-\mathrm{Mo}$ Steel Annealed at $500-1050^{\circ} \mathrm{C}$. In: Corrosion Science 41 (1999), pp. 1305-1322

[13] Terada, M.; Saiki, M.; Costa, I.; Padilha, A. F.: Microstructure and Intergranular Corrosion of Austenitic Stainless Steel 1.4970. In: Journal of Nuclear Materials 358 (2006), pp. 40-46

[14] Dománková, M.; Marek, P.; Magula, V.: Corrosion Resistance of 18Cr$12 \mathrm{Ni}-2,5 \mathrm{Mo}$ Steel Annealed at $500-900^{\circ} \mathrm{C}$. In: Acta Metallurgica Slovaca, Special Issue Vol. 13 (2007), pp. 487-492

[15] Bakajová, J.; Dománková, M.; Čička, R.; Eglsäer, S.; Janovec, J.: Influence of Annealing Conditions on Microstructure and Phase Occurrence in HighAlloy CrMnN Steels. In: Materials Characterization 61 (2010), pp. 969-974

[16] Matula, M.; Hyspecká, L.; Svoboda, M.; Vodarek, V.; Dagbert, C.; Galland, J.; Stonawska, Z.; Tuma, L.: Intergranular Corrosion of AISI 316L Steel. In: Materials Characterization 46 (2001), pp. 203-210 